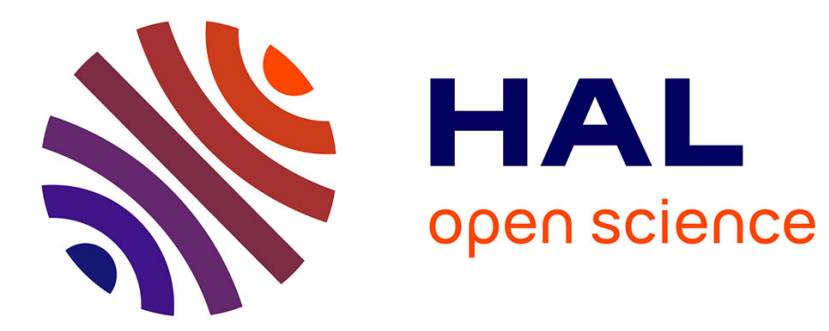

\title{
Water-Dispersible and Biocompatible Iron Carbide Nanoparticles with High Specific Absorption Rate
}

Alexis Bordet, Ryan F Landis, Yiwei Lee, Gulen y Tonga, Juan Manuel Asensio, Chenghsuan Li, Pier-Francesco Fazzini, Aikaterini Soulantika, Vincent M. Rotello, Bruno Chaudret

\section{To cite this version:}

Alexis Bordet, Ryan F Landis, Yiwei Lee, Gulen y Tonga, Juan Manuel Asensio, et al.. WaterDispersible and Biocompatible Iron Carbide Nanoparticles with High Specific Absorption Rate. ACS Nano, inPress. hal-02051157

\section{HAL Id: hal-02051157 https://hal.science/hal-02051157}

Submitted on 27 Feb 2019

HAL is a multi-disciplinary open access archive for the deposit and dissemination of scientific research documents, whether they are published or not. The documents may come from teaching and research institutions in France or abroad, or from public or private research centers.
L'archive ouverte pluridisciplinaire HAL, est destinée au dépôt et à la diffusion de documents scientifiques de niveau recherche, publiés ou non, émanant des établissements d'enseignement et de recherche français ou étrangers, des laboratoires publics ou privés. 


\title{
Water-Dispersible and Biocompatible Iron Carbide Nanoparticles with High Specific Absorption Rate
}

\author{
Alexis Bordett,Z, Ryan F. Landisf, YiWei Leeł, Gulen Y. Tongat, Juan M. Asensio ${ }^{\prime}$, \\ ChengHsuan Lił, Pier-Francesco Fazzini†, Katerina Soulantica†, Vincent M. Rotello $\neq *{ }^{*}$, and \\ Bruno Chaudrett, *
}

$\dagger$ LPCNO, Université de Toulouse, CNRS, INSA, UPS, 135 avenue de Rangueil, 31077 Toulouse, France.

$\$$ Department of Chemistry, University of Massachusetts Amherst, 710 North Pleasant Street, Amherst, MA 01003, USA.

*Dr. Bruno Chaudret: chaudret@insa-toulouse.fr

*Pr. Vincent M. Rotello: rotello@chem.umass.edu

\begin{abstract}
Magnetic nanoparticles are important tools for biomedicine, where they serve as versatile multifunctional instruments for a wide range of applications. Among these applications, magnetic hyperthermia is of special interest for the destruction of tumors and triggering of drug delivery. However, many applications of magnetic nanoparticles require high quality magnetic nanoparticles displaying high specific absorption rates, which remains a challenge today. We report here the functionalization and stabilization in aqueous media of highly magnetic $15 \mathrm{~nm}$ iron carbide nanoparticles featuring excellent heating power through magnetic induction. The challenge of achieving water solubility and colloidal stability was addressed by designing and using specific dopamine-based ligands. The resulting nanoparticles were completely stable for several months in water, phosphate, phosphate-buffered saline and serum-containing media. Iron carbide nanoparticles displayed high specific absorption rates (SAR) in water and viscous media (water/glycerol mixtures), even after extended exposition to water and oxygen (SAR up to. $1000 \mathrm{~W} \cdot \mathrm{g}^{-1}$ in water at $100 \mathrm{kHz}, 47 \mathrm{mT}$ ). The cytotoxicity and
\end{abstract}


cellular uptake of iron carbide nanoparticles could be easily tuned and were highly dependent on the chemical structure of the ligands used.

KEY WORDS. nanoparticles - iron carbide - magnetic hyperthermia - functionalization biocompatibility

Magnetic nanoparticles (NPs) are of strategic interest for several biomedical applications such as magnetic resonance imaging, ${ }^{1-3}$ magnetic hyperthermia ${ }^{1,4-6}$ and drug delivery. ${ }^{1,3,6}$ When exposed to an alternating magnetic field, suitable magnetic NPs undergo energy losses, thus producing heat. This phenomenon, called magnetic hyperthermia, is widely applied biomedically to destroy or weaken tumors, ${ }^{5}$ trigger drug delivery ${ }^{6}$ or improve drug efficacy. ${ }^{6}$ For magnetic hyperthermia to be efficient, however, magnetic NPs must be designed to maximize energy losses and thus the production of heat. The ability of NPs to heat through magnetic induction is commonly expressed by their specific absorption rate (SAR), and the objective is to reach high SAR at frequencies and amplitudes harmless for healthy tissues ${ }^{7,8}$ (typically $100 \mathrm{kHz}, 20 \mathrm{mT}$ ). Substantial effort has been dedicated to the synthesis of water stable and biocompatible NPs displaying high SARs. Given these requirements, iron-based nanoparticles appear to be promising candidates. ${ }^{9}$ Among them, iron oxide nanoparticles (IONPs) have been extensively studied. As a result, a significant number of synthetic procedures allowing the production of tunable iron oxide nanoparticles (size, shape, composition, etc.) are available. ${ }^{10,11}$ While commercially available IONPs generally display poor hyperthermia properties, very good SARs were reported for complex IONPs such as magnetite bacterial magnetosomes, ${ }^{12}$ maghemite nanoflowers ${ }^{13}$ or maghemite nanocubes. ${ }^{14,15}$ Despite their promising properties, these complex IONPs are not easily synthesized and exhibit a low saturation magnetization $\left(70-80 \mathrm{~A} \cdot \mathrm{m}^{2} \cdot \mathrm{kg}^{-1}\right.$ in the best cases). Iron has the highest saturation magnetization $\left(210 \mathrm{~A} \cdot \mathrm{m}^{2} \cdot \mathrm{kg}^{-1}\right)$ among all elements, and $\mathrm{Fe}(0) \mathrm{NPs}$ were shown to have very good SARs in organic solvents. ${ }^{16,17}$ Unfortunately, in the presence of oxygen or 
water, zero-valent iron NPs undergo very fast oxidation that dramatically affects their magnetic properties, reducing their utility as hyperthermic agents.

Iron carbide NPs provide a potential compromise between high saturation magnetization and stability in biological media. Several studies evidenced their potential for applications including magnetic hyperthermia, ${ }^{18-20}$ magnetic resonance imaging, ${ }^{21}$ catalysis. ${ }^{19,20,22-24} \mathrm{We}$ recently reported the synthesis of specific $\mathrm{Fe}_{2.2} \mathrm{C}$ ICNPs displaying exceptional SAR for applications in $\mathrm{CO}_{2}$ hydrogenation. ${ }^{20} \mathrm{We}$ report here the use of dopamine-based ligands to functionalize these ICNP structures and stabilize them efficiently in aqueous and biological media. Even after extended exposure to water and oxygen, these ICNPs present SARs higher than the ones of $\mathrm{Fe}(0)$ nanoparticles. The critical influence of the ligand structural design regarding the cytotoxicity and cellular-uptake of these ICNPs was also evidenced.

\section{RESULTS/DISCUSSION}

Monodisperse ICNPs $(15 \mathrm{~nm})$ were synthesized through the carbidization of preformed $\mathrm{Fe}(0)$ nanoparticles under $\mathrm{CO} / \mathrm{H}_{2}$, following an approach previously described by our group (Figure S1). ${ }^{20,25}$ These nanoparticles displayed excellent hyperthermia properties, with specific absorption rates (SARs) far higher than any iron oxide or iron(0) nanoparticles. However, due to the fatty acid and amine ligands of the as-prepared ICNPs, these particles are dispersible only in organic solvents, and further surface modification was mandatory to provide solubility and colloidal stability in aqueous environment. This challenge was addressed by replacing the initial hydrophobic stabilizers by specifically designed dopamine-based ligands (Figure 1) through a ligand exchange reaction. 


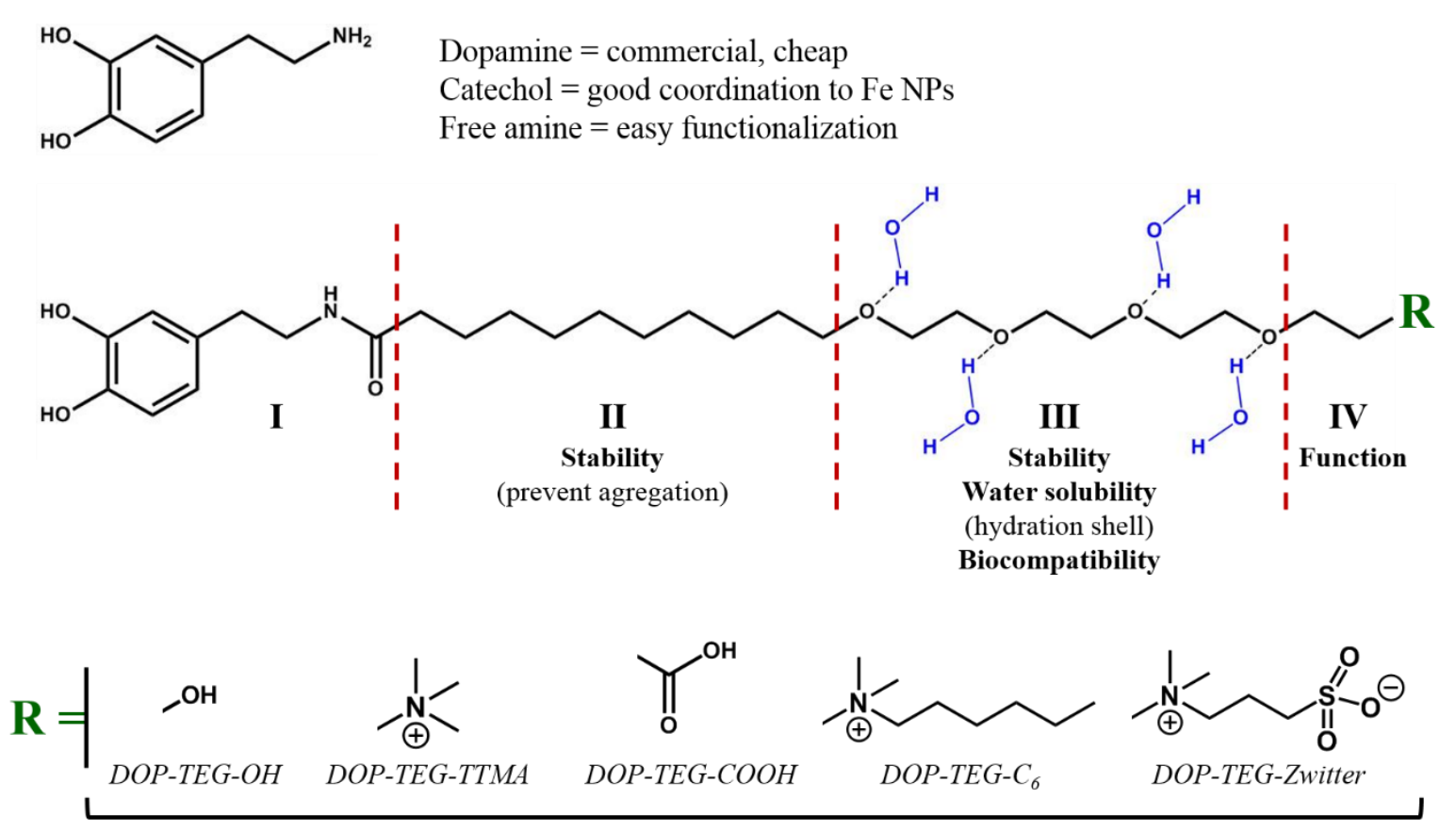

IV

Figure 1: Dopamine-based ligand structural design.

The ligand family was synthesized by adapting a previously described synthetic procedure ${ }^{26,27}$ starting from the dopamine derivative (I), which contains a catechol moiety. This catechol moiety is known to bind strongly to iron-based nanoparticle surfaces, ${ }^{28}$ and especially to iron oxide. However, dopamine derivatives were also recently described as suitable ligands for the stabilization of iron carbide nanoparticles $\left(\mathrm{Fe}_{5} \mathrm{C}_{2}\right)$ in water. ${ }^{18,21,29}$

The ligand structure contains a hydrophobic alkyl chain (II) which contributes to the stabilization of the NPs by fostering micelle-like hydrophobic assembly of the ligands. The tetraethylene glycol moiety (III) affords water solubility, biocompatibility and stability to the functionalized NPs. At the terminus, the function (IV) of the ligand can be easily modified to tune the behavior of the NPs in biological media. In a typical ligand exchange reaction, ICNPs $(10 \mathrm{mg})$ were dispersed in a mixture of dichloromethane and methanol (5/1). The water-soluble ligand (50 mg, 5 mass equivalents compared to ICNPs) was added to the dispersion, followed by triethylamine $(250 \mu \mathrm{L})$. The mixture was stirred overnight at room temperature. The work up of the reaction consisted of 3 washings with hexane followed by redispersion in water and 
purification by dialysis for $48 \mathrm{~h}$. The presence of the desired ligands on the surface of ICNPs was confirmed by LDI/MS experiments (Figure S2-6). ${ }^{27}$ In addition, thermo-gravimetric analysis of the ICNPs before and after the ligand exchange reaction was performed (Figure S7). The results showed that the characteristic signature of the long chain amine and acid ligands observed for as-synthesized ICNPs is missing in the case of water soluble ICNPs, and replaced by a signal attributed to the dopamine-based ligands. These observations indicate that the long chain amine and acid ligands were efficiently exchanged by the dopamine-derivatives during the ligand exchange reaction. This is in agreement with LDI-MS measurements, which did not evidence the presence of the initial hydrophobic ligands at the surface of the functionalized ICNPs (Figure S2-6). Taken together, these results suggest that the ICNPs are stabilized through the direct coordination of the dopamine-based ligands, rather than by their intercalation through hydrophobic interaction with remaining hexadecylamine and palmitic acid.

The stability of ICNPs functionalized with different types of ligands was investigated in multiple aqueous media (de-ionized water, phosphate buffer $5 \mathrm{mM}(\mathrm{PB})$, phosphate-buffered saline $150 \mathrm{mM}$ (PBS) and media containing 10\% bovine serum albumin (BSA) using dynamic light scattering (DLS) and transmission electron microscopy (TEM) analysis. Special interest was dedicated to the stability of ICNPs in PBS and serum media since their properties are closer to real biological conditions. The multiple types of ligands tested - commercial or synthesized - are disclosed in Table 1, together with their ability to bring ICNPs solubility and stability in aqueous media. 
Table 1. Summary of the ligands used to transfer ICNPs in aqueous media. ${ }^{\text {apB }}=$ Phosphate Buffer $5 \mathrm{mM}$; ${ }^{\text {b } P B S ~=~ P h o s p h a t e-B u f f e r e d ~ S a l i n e ~} 150 \mathrm{mM}$; ${ }^{\mathrm{c} S e r u m}$ containing 10\% Bovine Serum Albumin. (I) DOP-TEG-OH; (II) DOP-TEG-COOH; (III) DOP-TEG-TTMA; (IV) DOP-TEG-C6 ; (V) DOP-TEG-Zwitter.

Solubility and stability?

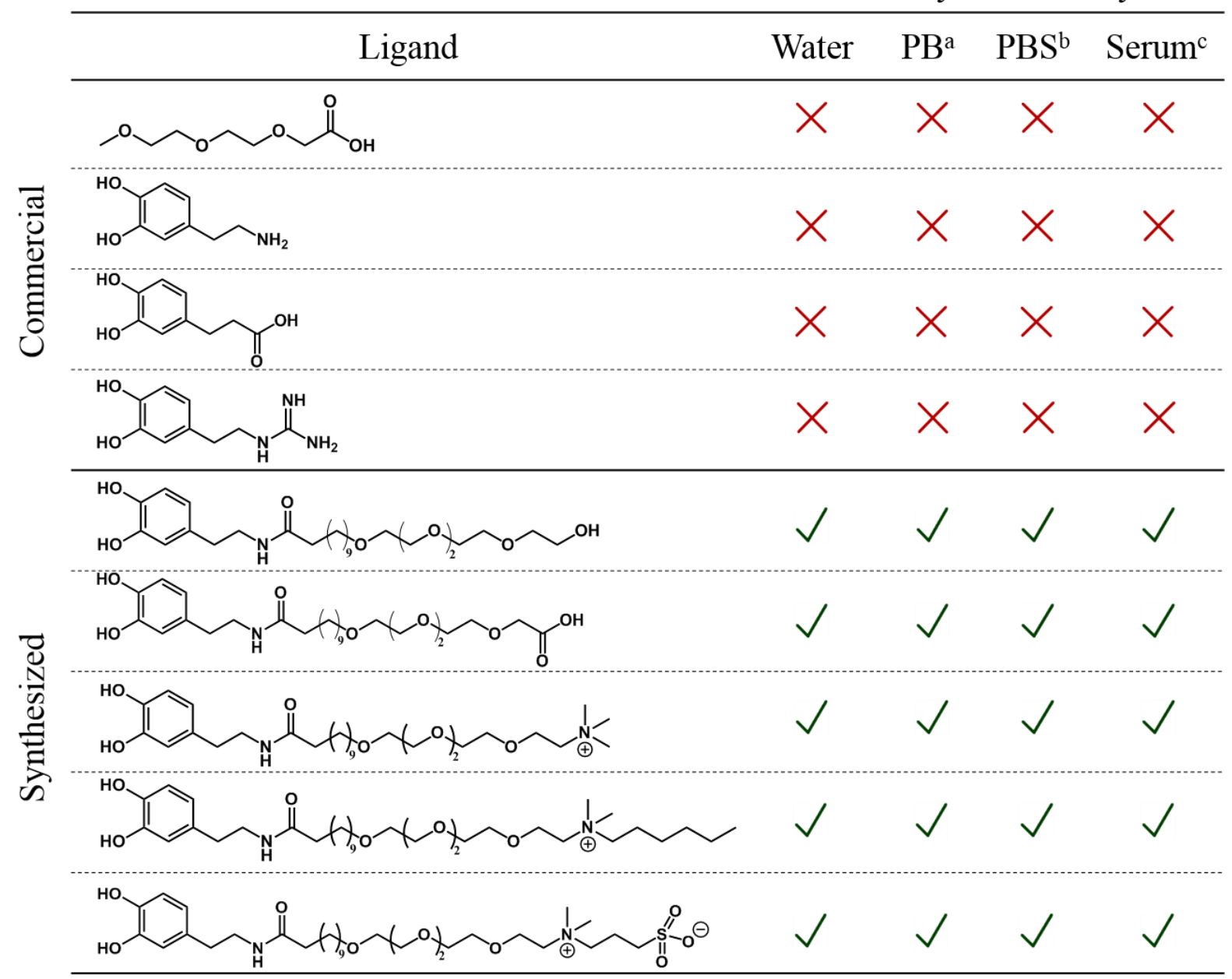

The first stability tests were performed with simple commercial ligands commonly used to stabilize magnetic NPs such as iron oxide in aqueous media. ${ }^{30-32}$ The results show that these ligands all fail to stabilize ICNPs in water, with the nanoparticles aggregating and precipitating in a few minutes. ICNPs thus require more advanced ligands than iron oxide NPs to be stable in water. The use of specifically synthesized dopamine-based ligands provided ICNPs with surprisingly good solubility and stability in all aqueous media studied. Among the five 
dopamine-based ligands presented in this table, we will focus on three particular ligands displaying respectively anionic $(D O P-T E G-C O O H)$, cationic $\left(D O P-T E G-C_{6}\right)$ and zwitterionic functionality (DOP-TEG-Zwitter).

For all three ligands, TEM analyses of the NPs before and after functionalization show that the NPs morphology is not affected by the ligand exchange or water exposure (Figure 2a and 2c). Interestingly, the stability of the functionalized ICNPs is such that they cannot be precipitated by magnet-assisted decantation. At suitable concentration, however, the solutions containing functionalized ICNPs exhibit a ferrofluid behavior (Figure 2d). According to DLS measurements, the ICNPs display very good colloidal stability in all types of aqueous media considered, with their hydrodynamic diameter remaining constant for more than one month (Figure 2e,g,i). While in all cases ICNPs appear to be individually stabilized in water, PB and PBS $\left(D_{\mathrm{H}} \sim 15-20 \mathrm{~nm}\right)$, the hydrodynamic diameter of the particles in serum media is significantly larger $(\sim 90 \mathrm{~nm})$. This increase in size is attributed to a partial aggregation of nanoparticles induced by the interactions between the ligands and the proteins of the serum, forming a protein corona shell. ${ }^{33}$ TEM analysis revealed the presence of $\sim 90 \mathrm{~nm}$ assemblies, thus confirming this hypothesis (Figure S8). 


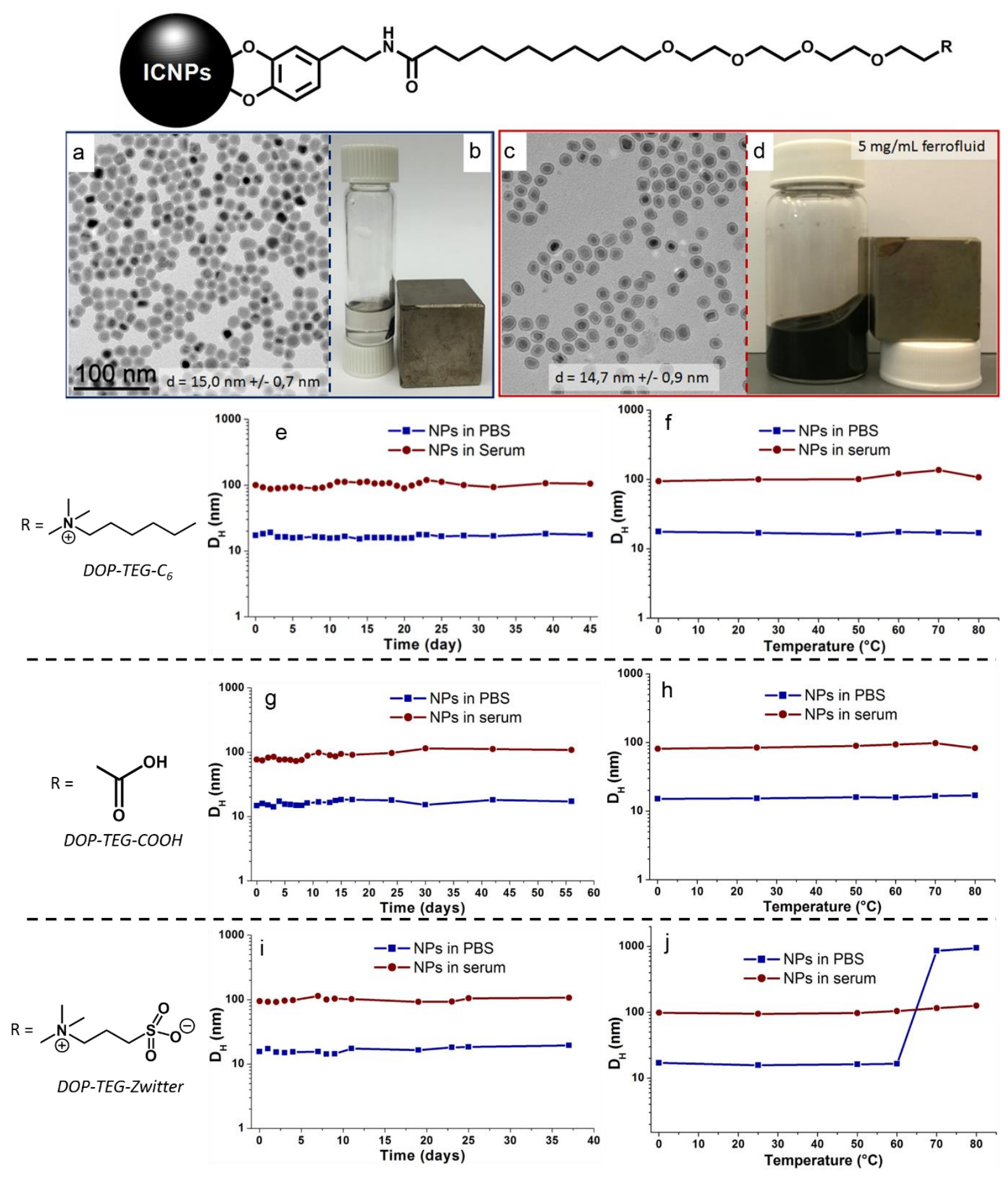

Figure 2: $(\mathrm{a}, \mathrm{b})$ ICNPs in mesitylene, $(\mathrm{c}, \mathrm{d})$ functionalized ICNPs (DOP-TEG-C 6 ligand) in water, similar results were obtained with the other two ligands. DLS analysis of functionalized ICNPs in aqueous media as a function of time and temperature: $(\mathrm{e}, \mathrm{f})$ functionalized with $D O P$ $T E G-C_{6} ;(\mathrm{g}, \mathrm{h})$ functionalized with $D O P-T E G-C O O H ;(i, j)$ functionalized with $D O P-T E G-$ Zwitter. PBS $=$ Phosphate-Buffered Saline. 
Interestingly, colloidal solutions containing functionalized ICNPs could be exposed to a wide range of temperatures without any aggregation or precipitation of the NPs (Figure $2 \mathrm{f}, \mathrm{h}, \mathrm{j}$ ). The only exception was observed with ICNPs functionalized with DOP-TEG-Zwitter, with an obvious aggregation and precipitation of the NPs after exposure to temperatures higher than $60^{\circ} \mathrm{C}$. The effects of the exposure of ICNPs to water and air on their structural and magnetic properties were investigated by XRD, VSM, and specific absorption rate (SAR) measurements (Figure 3 and S8).

a

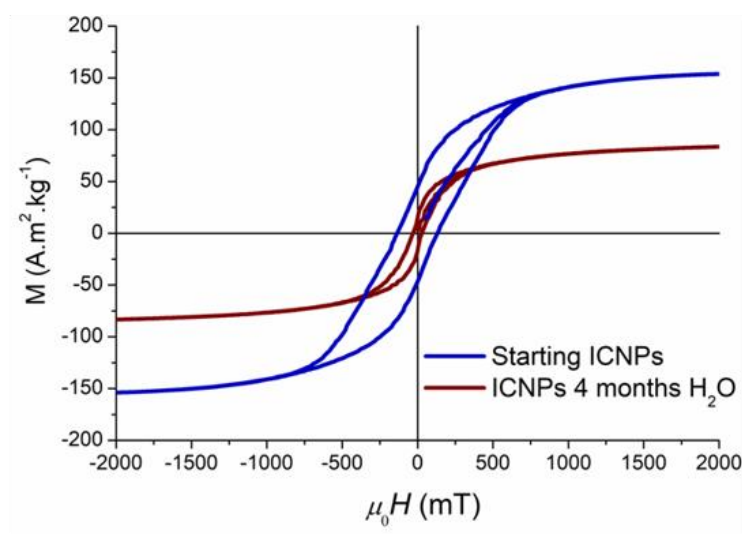

b

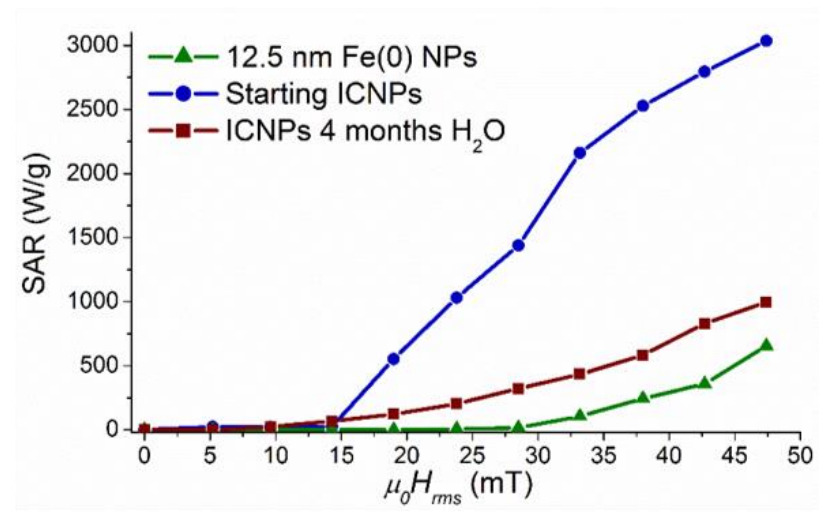

Figure 3: Magnetic properties of ICNPs before (as synthesized) and after 4 months exposure to water and air (functionalized ICNPs, DOP-TEG-C 6 ligand). (a) VSM analysis at $300 \mathrm{~K}$, (b) SAR measurement at $100 \mathrm{kHz}$. For comparison reasons, the SAR of as-synthesized Fe(0) NPs of similar size is also given.

XRD analysis evidences partial oxidation of the nanoparticles after a four-month exposure to water and air, but the pseudo-hexagonal $\mathrm{Fe}_{2.2} \mathrm{C}$ structure is still clearly visible (Figure $\mathrm{S} 9$ ). As a result of oxidation, VSM analysis (Figure 3a) shows that the saturation magnetization (90 A. $\left.\mathrm{m}^{2} \cdot \mathrm{kg}^{-1}\right)$ and the coercive field (32 mT) of ICNPs are significantly reduced as compared to starting nanoparticles (160 A. $\mathrm{m}^{2} . \mathrm{kg}^{-1}, 102 \mathrm{mT}$ respectively). Nevertheless, the SAR of these functionalized NPs in water remain high, reaching ca. $1000 \mathrm{~W} \cdot \mathrm{g}^{-1}$ at $47 \mathrm{mT}, 100 \mathrm{kHz}$. Indeed, their magnetic heating properties even after partial oxidation are still better than those of 12.5 
nm $\mathrm{Fe}(0)$ NPs synthesized and kept under oxygen- and water-free conditions (Figure 3b). Thus, despite a partial oxidation and modification of their magnetic properties, ICNPs maintain high SARs values after 4 months in water and under air, making them promising candidates for biomedical applications in which magnetic heating is required.

Having a library of ligands displaying different functions and charges allows tuning of the cytotoxicity and cellular-uptake of the [ICNPs-Ligand] couple. The cytotoxicity against HeLa cells of ICNPs functionalized with the three different ligands was investigated for several incubation times and ICNPs concentrations ranging from 0.01 to $2 \mathrm{mg} \cdot \mathrm{mL}^{-1}$ (Figure 4).

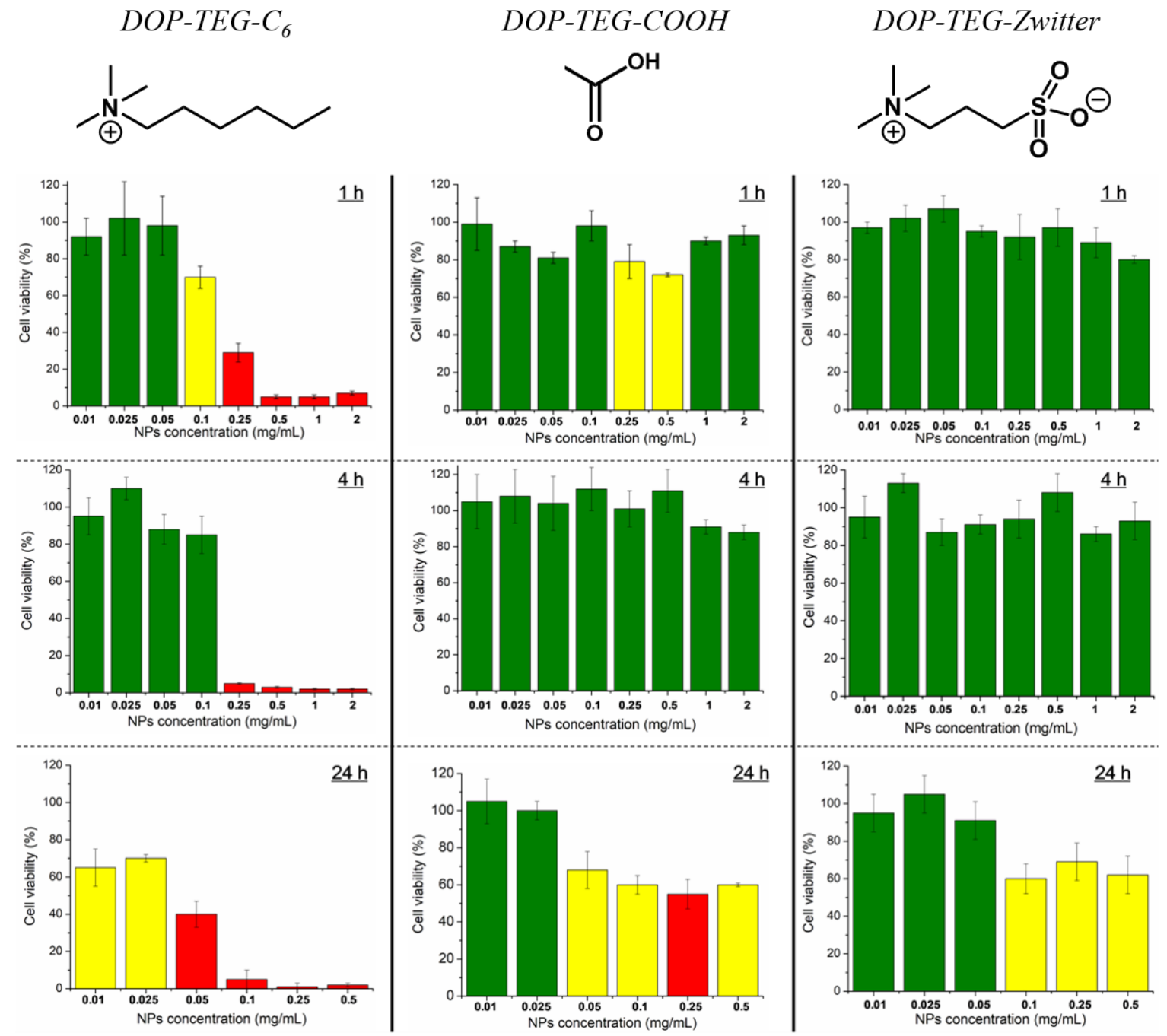

DOP-TEG-COOH

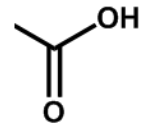

DOP-TEG-Zwitter

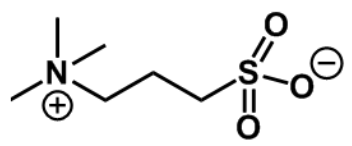

Figure 4: Cytotoxicity of different [ICNPs-ligand] systems as a function of the incubation time and of the ICNPs concentration of the incubation media. Color code: [100-80\%]: green; [8060\%]: yellow; [60-0\%]: red. 
ICNPs functionalized by the cationic ligand $D O P-T E G-C_{6}$ display an acute toxicity even for short incubation times. This toxicity can be attributed to the $\mathrm{C}_{6}$ hydrophobic chain carried by the quaternary ammonium group. In sharp contrast, the ligands $D O P-T E G-C O O H$ and $D O P$ TEG-Zwitter provide ICNPs with a very good biocompatibility. No significant cytotoxicity was observed for incubation times up to $4 \mathrm{~h}$ at any of the concentrations in NPs of the incubation media. For $24 \mathrm{~h}$ incubation, the biocompatibility of ICNPs is very good up to $0.025 \mathrm{mg} \cdot \mathrm{mL}^{-1}$, the toxicity increasing slightly for higher concentrations. These values are comparable to what can be observed with typical biocompatible iron oxide nanoparticles. ${ }^{34}$ Concerning iron carbide nanoparticles, studies are scarce, and until now limited to $\mathrm{Fe}_{5} \mathrm{C}_{2}$ nanoparticles. For example, Xie et al observed a $20 \%$ cellular death after $24 \mathrm{~h}$ incubation with $0.025 \mathrm{mg} \cdot \mathrm{mL}^{-1}$ of polydisperse polymer coated $\mathrm{Fe}_{5} \mathrm{C}_{2}$ nanoparticles. ${ }^{21}$ With similar nanoparticles coated with BSA, Hou et al evidenced the death of $10 \%$ of the cells after $24 \mathrm{~h}$ incubation with a NPs concentration of $0.025 \mathrm{mg} \cdot \mathrm{mL}^{-1}{ }^{29}$ The biocompatibility of our system is significantly better, since no cytotoxicity was evidenced when cells were incubated for $24 \mathrm{~h}$ with $0.025 \mathrm{mg} \cdot \mathrm{mL}^{-1}$ $\mathrm{Fe}_{2.2} \mathrm{C}$ ICNPs functionalized with DOP-TEG-COOH and Zwitter. These results clearly evidence the critical role played by the ligands in the final biocompatibility of the couple [ICNPs-Ligand]. The three systems were further characterized through a cellular uptake study. HeLa cells were incubated for $4 \mathrm{~h}$ in media containing different concentration of functionalized ICNPs. After incubation, the cells were washed with PBS, and subjected to ICP analysis to determine their iron content (Table 2). 
Table 2. Cellular-uptake of different [ICNPs-ligand] systems as a function of the concentration of the incubation media (incubation time $=4 \mathrm{~h}$ ).

\begin{tabular}{|c|c|c|c|c|}
\hline Ligand & $\begin{array}{l}\text { NPs conc. } \\
\left(\mathrm{mg} \cdot \mathrm{mL}^{-1}\right)\end{array}$ & $\begin{array}{c}\text { Viability } \\
(\%)\end{array}$ & $\begin{array}{c}\mathbf{p p b}_{\mathrm{Fe}} / \mathbf{w e l l} \\
{[\mathrm{error} \%]}\end{array}$ & $\begin{array}{l}\mathbf{p g}_{\mathrm{Fe}} / \text { cell } \\
\text { [error\%] }\end{array}$ \\
\hline Control experiment & - & 100 & $17[8]$ & $4[9]$ \\
\hline \multirow[t]{3}{*}{$D O P-T E G-C_{6}(\mathbf{I V})$} & 0.5 & 2 & $169[34]$ & $44[36]$ \\
\hline & 1.0 & 2 & $349[31]$ & $88[29]$ \\
\hline & 2.0 & 3 & $821[9]$ & $213[8]$ \\
\hline \multirow{3}{*}{$D O P-T E G-C O O H$ (II) } & 0.5 & 100 & 9 [15] & $2[14]$ \\
\hline & 1.0 & 90 & $14[9]$ & $4[8]$ \\
\hline & 2.0 & 86 & 10 [39] & $2[40]$ \\
\hline \multirow[t]{3}{*}{ DOP-TEG-Zwitter (V) } & 0.5 & 100 & $276[2]$ & $69[4]$ \\
\hline & 1.0 & 86 & $551[3]$ & $140[3]$ \\
\hline & 2.0 & 93 & 234 [13] & $60[12]$ \\
\hline
\end{tabular}

For the ICNP-DOP-TEG-C6 system, the concentration of iron inside the cells increases with the increase of the concentration, evidencing the ability of this system to easily enter in the cells. The high cellular-uptake of ICNPS-DOP-TEG-C6 is not surprising, since NPs with positively charged surface interact strongly with the negatively charged surface of cells. ${ }^{35,36}$ The ICNPs-DOP-TEG-Zwitter system displays a similar behavior, though a drop in the cellular uptake can be observed for the most concentrated incubation medium $\left(2 \mathrm{mg} \cdot \mathrm{mL}^{-1}\right)$. This decrease is attributed to a partial aggregation and precipitation of ICNPs in the incubation medium at this concentration. The cellular-uptake of ICNPs functionalized by $D O P-T E G-C_{6}$ and Zwitter is in the same range than what is usually observed with conventional iron oxide nanoparticles. ${ }^{37,38}$ 
In strong contrast, no significant cellular uptake was observed for ICNPs functionalized by $D O P-T E G-C O O H$. This result is expected since at the $\mathrm{pH}$ at which this study was performed (7.2), the ligands are under the carboxylate form (anionic). Both ICNPs surface and cells surface are thus negatively charged, and the repulsive electrostatic interactions between them prevent the penetration of the NPs in the cells. These observations prove once again that the behavior of nanoparticles in biological conditions is highly impacted by the ligands that are present at their surface.

ICNPs functionalized with the DOP-TEG-Zwitter ligand appear as promising candidates for medical magnetic hyperthermia since they combine high SAR in water, low cytotoxicity and good cellular uptake. However, the environment in cells and tumors is known to have a higher viscosity than pure water, which can affect the heating properties of magnetic nanoparticles. To investigate the influence of the medium's viscosity on the heating power of ICNPs, their SAR was measured in aqueous solutions containing different concentrations of glycerol (Figure 5).

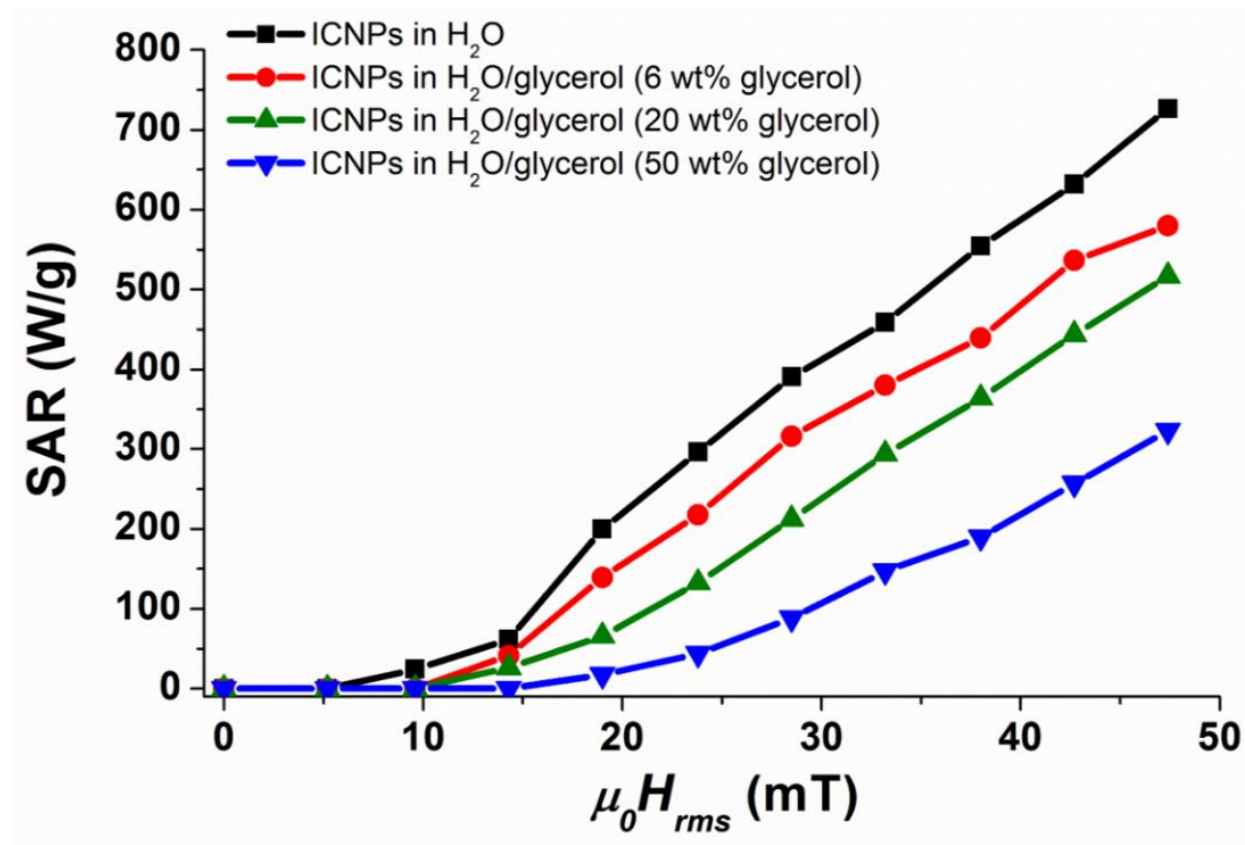

Figure 5. SAR measurement at $100 \mathrm{kHz}$ for ICNPs (DOP-TEG-Zwitter ligand) dispersed in media with different viscosities. 
The results show that the SAR of ICNPs is slowly decreasing when the proportion of glycerol is increasing, evidencing a dependence of the SAR on the solvent's viscosity. Nevertheless, the SAR values remain high (exceeding $515 \mathrm{~W} / \mathrm{g}$ up to $20 \mathrm{wt} \%$ glycerol, and $320 \mathrm{~W} / \mathrm{g}$ at $50 \mathrm{wt} \%$ glycerol $(47 \mathrm{mT}, 100 \mathrm{kHz}))$, making these NPs of interest for practical applications.

To finish, ICNPs functionalized by the DOP-TEG-Zwitter ligand were further characterized by high resolution TEM and STEM-HAADF-EDX at $\mathrm{t}_{0}$, and after 40 days in water (Figure 6).

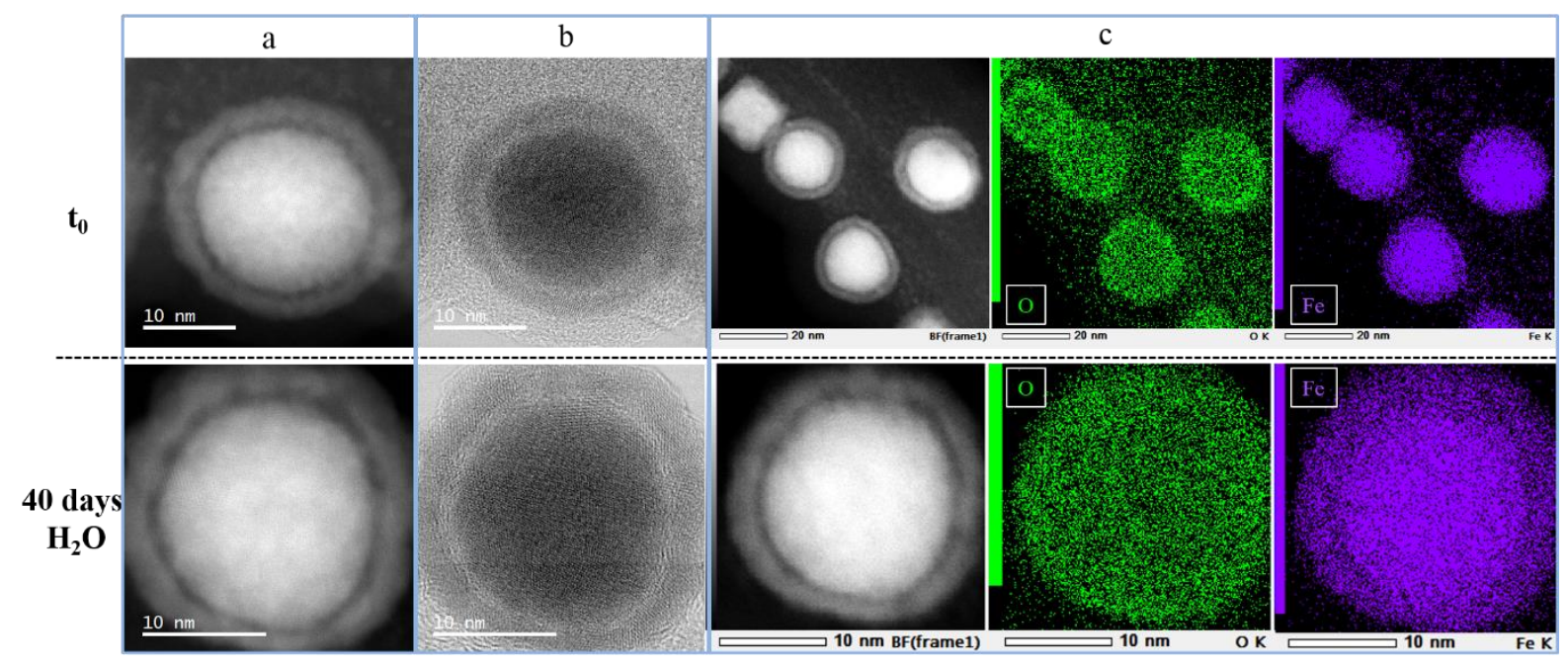

Figure 6. High resolution electron microscopy of ICNPs in water: at $\mathrm{t}_{0}$ after functionalization, and after 40 days in water. a) High Angle Annular Dark Field Scanning Electron Microscopy (STEM-HAADF); b) Bright field high resolution TEM; c) STEM-HAADF-EDX (Energy Dispersive X-ray) elemental mapping.

The results show in both cases a core-shell structure with an oxygen rich shell and an iron rich core, suggesting the formation of a thin shell of iron oxide (ca. $2 \mathrm{~nm}$ ) around the iron carbide core. The presence of this oxide shell already at $t_{0}$ shows that the surface oxidation of ICNPs is very fast when they are exposed to air and water during the ligand exchange reaction. Interestingly, no significant difference can be observed between the ICNPs at $\mathrm{t}_{0}$ and after 40 days in water, indicating that ICNPs can be conserved a long time in aqueous solution without suffering from advanced oxidation and losing their advantageous magnetic properties. In 
addition, their ability to undergo surface oxidation suggest that they could be slowly degraded by liver cells, which is an important factor when considering practical in-vivo applications. ${ }^{39-40}$

\section{CONCLUSIONS}

In summary, we show that engineered dopamine-based ligands are suitable for the transfer of magnetic iron carbide nanoparticles into water. The functionalized ICNPs are highly soluble and stable several months in all types of aqueous media investigated (water, PB, PBS, Serum). Despite partial oxidation, ICNPs maintain good magnetic properties, and most importantly high SAR in water and water-glycerol mixtures. The nature of the ligands is a key parameter governing the cytotoxicity and cellular-uptake of the functionalized nanoparticles. Through proper choice of ligand structure we were in particular able to obtain [ICNPs-ligand] systems displaying very low cytotoxicity, and entering easily or not in the cells.

The biocompatibility of these ICNPs is comparable to the best of the IONs, with their superior magnetic properties making them promising candidates for biomedical applications, and in particular medical magnetic hyperthermia.

\section{METHODS/EXPERIMENTAL}

\section{General}

All syntheses of iron-based nanoparticles were performed under argon either by using Schlenk techniques or in a glove box. Mesitylene (99\%), toluene (99\%), and tetrahydrofuran (99\%) were purchased from VWR Prolabo, then purified on alumina desiccant and degassed through three freeze-pump-thaw cycles. The commercial products, hexadecylamine (HDA, 99\%) and palmitic acid (PA, 99\%) were purchased from Sigma-Aldrich. These compounds were used without any additional purification. Dopamine-based ligands were synthesized following methods reported in the literature. Ligand exchange reactions were performed using methanol and dichloromethane degassed by nitrogen bubbling. 


\section{Characterization}

The size and the morphology of as-synthesized nanoparticles were studied by transmission electronic microscopy TEM. TEM grids were prepared by drop casting a colloidal solution containing as prepared NPs on a copper grid covered with amorphous carbon. Conventional bright-field images were performed using JEOL microscopes (Model 1400 and 2010) working at $120 \mathrm{kV}$ and $200 \mathrm{kV}$ respectively. HR-TEM, STEM-HAADF and EDX measurements were carried out using a JEOL JEM-ARM200F Cold FEG working at $200 \mathrm{kV}$. XRD measurements were performed on a PANalytical Empyrean diffractometer using Co-K $\alpha$ radiation $(\lambda=0.1789$ $\mathrm{nm})$ at $45 \mathrm{kV}$ and $40 \mathrm{~mA}$. Magnetic measurements were performed on a Vibrating Sample Magnetometer (VSM, Quantum Device PPMS Evercool II). XRD and VSM studies were carried out on compact powder samples as well as on diluted assemblies that were prepared and sealed under argon atmosphere. DLS analyses were performed on a Malvern Zetasizer Nano ZS equipment $([0,3 \mathrm{~nm}-10 \mu \mathrm{m}])$. Laser He-Ne $633 \mathrm{~nm}, 4 \mathrm{~mW}$ maxi). Synthesized organic ligands were characterized by ${ }^{1} \mathrm{H}$ NMR (Bruker $400 \mathrm{MHz}$ ). LDI-MS were performed on a Bruker Autoflex III MALDI-TOF mass spectrometer equiped with a Smartbeam 2 laser and a MTP 384 steel target. Analysis conditions : ion source $1=19.00 \mathrm{kV}$, ion source $2=16.60 \mathrm{kV}$, lens voltage $=8.44 \mathrm{kV}$, reflector voltage $=20.00 \mathrm{kV}$, reflector voltage $2=9.69 \mathrm{kV}$, pulsed ion extraction time $=10 \mathrm{~ns}$, suppression $=100 \mathrm{Da}$. TGA were carried out with a Mettler Toledo “TGA/DSC 1 STAR System".

\section{Hyperthermia measurements}

For a typical hyperthermia experiment, an air-tight tube containing about $10 \mathrm{mg}$ of powder of iron carbide or iron/iron carbide nanocrystals dispersed in $0.5 \mathrm{ml}$ of mesitylene was filled under inert atmosphere. The tube was then placed in a calorimeter containing $2.5 \mathrm{ml}$ of deionized water, the temperature of which was monitored during the experiment. The calorimeter was exposed to an alternative magnetic field for a time varying between 10 and $40 \mathrm{~s}$ so that the temperature rise never exceeded $20^{\circ} \mathrm{C}$. The temperature rise at the end of the magnetic field 
application was always measured after shaking the calorimeter to ensure the temperature homogeneity, which was measured by two probes (at the top and the bottom of the calorimeter). The temperature rise was determined after this process from the mean slope of the $\Delta \mathrm{T} / \Delta \mathrm{t}$ function. Then the raw SAR values were calculated using the expression:

$$
S A R=\frac{\sum_{\mathrm{i}} \mathrm{C}_{\mathrm{pi}} \mathrm{m}_{\mathrm{i}}}{\mathrm{m}_{\mathrm{Fe}}} \times \frac{\Delta \mathrm{T}}{\Delta \mathrm{t}}
$$

where $C \mathrm{p}_{\mathrm{i}}$ and $\mathrm{m}_{\mathrm{i}}$ are the specific heat capacity and the mass for each component respectively $\left(C \mathrm{p}=449 \mathrm{~J} \mathrm{~kg}^{-1} \mathrm{~K}^{-1}\right.$ for Fe NPs, $C \mathrm{p}=1750 \mathrm{~J} \mathrm{~kg}^{-1} \mathrm{~K}^{-1}$ for mesitylene, $C \mathrm{p}=4186 \mathrm{~J} \mathrm{~kg}^{-1} \mathrm{~K}^{-1}$ for water, $C \mathrm{p}=2430 \mathrm{~J} \mathrm{~kg}^{-1} \mathrm{~K}^{-1}$ for glycerol and $C \mathrm{p}=720 \mathrm{~J} \mathrm{~kg}^{-1} \mathrm{~K}^{-1}$ for glass), and $\mathrm{m}_{\mathrm{Fe}}$ is the mass of the pure iron carbide nanocristals.

\section{Synthesis of $\mathrm{Fe}(0)$ nanoparticles}

In a typical synthesis, the $\mathrm{Fe}(0) \mathrm{NPs}$ were prepared as follows: in the glove box, $0.65 \mathrm{mmol}$ of PA (333.2 $\mathrm{mg})$ and $0.5 \mathrm{mmol}$ of HDA $(241.5 \mathrm{mg})$ were added to a green solution of $0.5 \mathrm{mmol}$ $\left\{\mathrm{Fe}\left[\mathrm{N}\left(\mathrm{SiMe}_{3}\right)_{2}\right]_{2}\right\}_{2}(376.5 \mathrm{mg})$ in $20 \mathrm{ml}$ of distilled and degassed mesitylene in a Fischer Porter bottle. The bottle was then pressurized with dihydrogen ( 2 bar) and placed in an oil bath at $150^{\circ} \mathrm{C}$ for $48 \mathrm{~h}$ under magnetic stirring $(400 \mathrm{rpm})$. After $48 \mathrm{~h}$, the reaction was stopped and the NPs were recovered by decantation assisted by a magnet, and washed 3 times $(3 * 10 \mathrm{~mL})$ with toluene and 3 times $(3 * 10 \mathrm{~mL})$ with THF. The NPs were then dried under vacuum. According to elemental analysis, the black powder obtained contains $\sim 50 \mathrm{wt} \%$ of iron. The NPs were further characterized by XRD, VSM and TEM.

\section{Synthesis of iron carbide nanoparticles (ICNPs)}

Iron carbide NPs were obtained through the carbidization of preformed $\mathrm{Fe}(0) \mathrm{NPs}$. In a typical experiment, $12.5 \mathrm{~nm} \mathrm{Fe}(0) \mathrm{NPs}(50 \mathrm{mg}, 0.45 \mathrm{mmol}$ of iron) were dispersed in mesitylene (9 $\mathrm{mL}$ ), and the mixture was pressurized with $\mathrm{CO} / \mathrm{H}_{2}$ (2 bar $/ 2$ bar $)$ at $150^{\circ} \mathrm{C}$ for $140 \mathrm{~h}$. At the 
end of the reaction, the NPs were recovered by decantation assisted by a magnet and were washed 3 times with toluene $(3 \times 5 \mathrm{~mL})$. The NPs were then dried under vacuum. According to the elemental analysis, the black powder obtained contains $\sim 70 \mathrm{wt} \%$ of iron. The NPs were further characterized by XRD, VSM and TEM.

\section{Ligand exchange reaction}

In a typical ligand exchange reaction, ICNPs were dispersed in a mixture of dichloromethane and methanol (5/1). The water-soluble ligand (5 mass equivalents) was added to the dispersion, followed by triethylamine $(250 \mu \mathrm{L})$ addition. The mixture was stirred overnight at room temperature. The work up of the reaction consisted of 3 washing cycles with hexane, followed by redispersion in water and purification by dialysis during $48 \mathrm{~h}$. The presence of the desired ligands at the surface of the ICNPs was confirmed by LDI/MS experiments.

\section{Cell viability assay}

Cell viability (HeLa cells) was measured by quantifying the reduction of a dye indicator alamar blue. Alamar blue is a dye that takes advantage of mitochondrial reductases to change from oxidized indigo blue state to reduced pink state. This dye has been successfully used in various cell cultures to measure cell viability. Briefly, cells in 4 well plates are loaded with $300 \mathrm{~mL}$ culture medium containing 10\% alamar blue (Biosource International) and incubated in $37^{\circ} \mathrm{C}$, $5 \% \mathrm{CO}_{2}$ for $2 \mathrm{~h} .100 \mathrm{~mL}$ medium from each well was then transferred to a 96 well plate and subjected to measurement. The reduction of alamar blue was measured and calculated by a SpectroMax M5 micro-plate reader (Molecular Device) at $570 \mathrm{~nm}$ and $600 \mathrm{~nm}$ wavelengths.

\section{AUTHOR INFORMATION}

\section{Present Addresses}


ZMax Planck Institute for Chemical Energy Conversion, Stiftstraße 34-36, 45470 Mülheim an der Ruhr, Germany.

\section{ACKNOWLEDGMENTS}

The authors thank ERC Advanced Grant (NANOSONWINGS 2009-246763) and ERC Advanced Grant (MONACAT 2015-694159) for financial support. VR acknowledges the National institutes of Health (US) (EB022641).

SUPPORTING INFORMATION. Detailed methods and experimental section, additional characterization of the nanoparticles and ligands.

\section{REFERENCES}

1 Fernandes Cardoso, V.; Francesko, A.; Ribeiro, C.; Banobre-Lopez, M.; Martins, P.; Lanceros-Mendez, S. Advances in Magnetic Nanoparticles for Biomedical Applications. Adv. Healthcare Mater. 2018, 7, 1700845.

2 Pankhurst, Q. A.; Connolly, J.; Jones, S. K.; Dobson, J. Applications of Magnetic Nanoparticles in Biomedicine. J. Phys. D: Appl. Phys. 2003, 36, R167-R181.

3 Sun, C.; Lee, J. S. H.; Zhang, M. Magnetic Manoparticles in MR Imaging and Drug Delivery. Adv. Drug Delivery Rev. 2008, 60, 1252-1265.

4 Lee, J.-H.; Jang, J.-T.; Choi, J.-S.; Moon, S. H.; Noh, S.-H.; Kim, J.-W.; Kim, J.-G.; Kim, I.-S.; Park, K. I.; Cheon, J. Exchange-Coupled Magnetic Nanoparticles for Efficient Heat Induction. Nat. Nanotechnol. 2011, 6, 418-422.

5 Salunkhe, A.B.; Khot, V.M.; Pawar, S.H. Magnetic Hyperthermia with Magnetic Nanoparticles: a Status Review. Curr. Top. Med. Chem. 2014, 14, 572-594.

6 Kumar, C. S. S. R.; Mohammad, F. Magnetic Nanomaterials for Hyperthermia-Based Therapy and Controlled Drug Delivery. Adv. Drug Delivery Rev. 2011, 63, 789-808.

7 Giustini, A. J.; Petryk, A. A.; Cassim, S. M.; Tate, J. A.; Baker, I.; Hoopes, P. J. Magnetic Nanoparticle Hyperthermia in Cancer Treatment. Nano LIFE 2010, 1, 1-23.

8 Hergt, R.; Dutz, S. Magnetic Particle Hyperthermia-Biophysical Limitations of a Visionary Tumour Therapy. J. Magn. Magn. Mater. 2007, 311, 187-192. 
9 Hergt, R.; Dutz, S.; Müller, R.; Seiberger, M. Magnetic Particle Hyperthermia: Nanoparticle Magnetism and Materials Development for Cancer Therapy. J. Phys.: Condens. Matter 2006, 18, 38.

10 Gupta, A. K.; Gupta, M. Synthesis and Surface Engineering of Iron Oxide Nanoparticles for Biomedical Applications. Biomaterials 2005, 26, 3995-4021.

11 Laurent, S.; Forge, D.; Port, M.; Roch, A.; Robic, C.; Elst, L. V.; Muller, R. N. Magnetic Iron Oxide Nanoparticles: Synthesis, Stabilization, Vectorization, Physicochemical Characterizations, and Biological Applications. Chem. Rev. 2008, 108, 2064-2110.

12 Hergt, R.; Hiergeist, R.; Zeisberger, M.; Schüler, D.; Heyen, U.; Hilger, I.; Kaiser, W. A. Magnetic Properties of Bacterial Magnetosomes As Potential Diagnostic and Therapeutic Tools. J. Magn. Magn. Mater. 2005, 293, 80-86.

13 Hugounenq, P.; Levy, M.; Alloyeau, D.; Lartigue, L.; Dubois, E.; Cabuil, V.; Ricolleau, C.; Rous, S.; Wilhelm, C.; Gazeau, F.; Bazzi, R. Iron Oxide Monocrystalline Nanoflowers for Highly Efficient Magnetic Hyperthermia. J. Phys. Chem. C 2012, 116, 15702-15712.

14 Guardia, P.; Di Corato, R.; Lartigue, L.; Whilhelm, C.; Espinosa, A.; Garcia-Hernandez, M.; Gazeau, F.; Manna, L.; Pellegrino, T. Water-Soluble Iron Oxide Nanocubes with High Values of Specific Absorption Rate for Cancer Cell Hyperthermia Treatment. ACS Nano 2012, 6, 3080-3091.

15 Guardia, P.; Riedinger, A.; Nitti, S.; Pugliese, G.; Marras, S.; Genovese, A.; Materia, M. E.; Lefevre, C.; Manna, L.; Pellegrino, T. One Pot Synthesis of Monodisperse Water Soluble Iron Oxide Nanocrystals with High Values of the Specific Absorption Rate. $J$. Mater. Chem. B 2014, 2, 4426.

16 Mehdaoui, B.; Meffre, A.; Lacroix, L-M.; Carrey, J.; Lachaize, S.; Gougeon, M.;Respaud, M.; Chaudret, B. Large Specific Absorption Rates in the Magnetic Hyperthermia Properties of Metallic Iron Nanocubes. J. Magn. Magn. Mater. 2010, 322 , L49-L52.

17 Mehdaoui, B.; Meffre, A.; Lacroix, L-M.; Carrey, J.; Lachaize, S.; Gougeon, M.; Respaud, M.; Chaudret, B. Large Specific Absorption Rates in the Magnetic Hyperthermia Properties of Metallic Iron Nanocubes. J. Appl. Phys. 2010, 107, 09A324.

18 Yu, J.; Chen, F.; Gao, W.; Ju, Y.; Chu, X.; Che, S.; Sheng, F.; Hou, Y. Iron Carbide Nanoparticles: an Innovative Nanoplatform for Biomedical Applications. Nanoscale Horiz. 2017, 2, 81-88.

19 Meffre, A.; Mehdaoui, B.; Kelsen, V.; Fazzini, P. F.; Carrey, J.; Lachaize, S.; M.; Respaud, M.; Chaudret, B. A Simple Chemical Route toward Monodisperse Iron Carbide Nanoparticles Displaying Tunable Magnetic and Unprecedented Hyperthermia Properties. Nano Lett. 2012, 12, 4722-4728. 
20 Bordet, A.; Lacroix, L.-M.; Fazzini, P. F.; Carrey, J.; Soulantica, K.; Chaudret, B. Magnetically Induced Continuous $\mathrm{CO}_{2}$ Hydrogenation Using Composite Iron Carbide Nanoparticles of Exceptionally High Heating Power. Angew. Chem., Int. Ed. 2016, 55, 15894-15898.

21 Tang, W.; Zhen, Z.; Yang, C.; Wang, L.; Cowger, T.; Chen, H.; Todd, T.; Hekmatyar, K.; Zhao, Q.; Hou, Y.; Xie, J. $\mathrm{Fe}_{5} \mathrm{C}_{2}$ Nanoparticles with High MRI Contrast Enhancement for Tumor Imaging. Small 2014, 10, 1245-1249.

22 Yang, C.; Zhao, H.; Hou, Y.; Ma, D. Fe ${ }_{5} \mathrm{C}_{2}$ Nanoparticles: A Facile Bromide-Induced Synthesis and As an Active Phase for Fischer-Tropsch Synthesis. J. Am. Chem. Soc. 2012, 134, 15814 .

23 Niether, C.; Faure, S.; Bordet, A.; Deseure, J.; Chatenet, M.; Carrey, J.; Chaudret, B.; Rouet, A. Improved Water Electrolysis Using Magnetic Heating of Core-Shell FeC@Ni Nanoparticles. Nat. Energy 2018, 3, 476-483.

24 Bordet, A.; Asensio, J. M.; Soulantica, K.; Chaudret, B. Enhancement of Carbon Oxides Hydrogenation on Iron-Based Nanoparticles by In-Situ Water Removal. ChemCatChem 2018, 10, 4047-4051.

25 Bordet, A.; Lacroix, L.-M.; Soulantica, K.; Chaudret, B. A New Approach to the Mechanism of Fischer-Tropsch Syntheses Arising from Gas Phase NMR and Mass Spectrometry. ChemCatChem 2016, 8, 127-1731.

26 Miranda, O. R.; Chen, H.-T.; You, C.-C.; Mortenson, D. E.; Yang, X.-C.; Bunz, U. H. F.; Rotello, V. M. Enzyme-Amplified Array Sensing of Proteins in Solution and in Biofluids. J. Am. Chem. Soc. 2010, 132, 5285-5289.

27 Yan, B.; Jeong, Y.; Mercante, L. A.; Yesilbag Tonga, G.; Kim, C.; Zhu, Z.-J.; Vachet, R. W.; Rotello, V. M. Characterization of Surface Ligands on Functionalized Magnetic Nanoparticles Using Laser Desorption/Ionization Mass Spectrometry (LDI-MS). Nanoscale 2013, 5, 5063.

28 Hong, R.; Fischer, N. O.; Emrick, T.; Rotello, V. M. Surface PEGylation and Ligand Exchange Chemistry of FePt Nanoparticles for Biological Applications. Chem. Mater. 2005, 17, 4617-4621.

29 Yu, J.; Ju, Y.; Zhao, L.; Chu, X.; Yang, W.; Tian, Y.; Sheng, F.; Lin, J.; Liu, F.; Dong, Y.; Hou, Y. Multistimuli-Regulated Photochemothermal Cancer Therapy Remotely Controlled via $\mathrm{Fe}_{5} \mathrm{C}_{2}$ Nanoparticles. ACS Nano 2015, 10, 159-169.

30 Korpany, K. V.; Habib, F.; Murugesu, M.; Blum, A. S. Stable Water-Soluble Iron Oxide Nanoparticles Using Tiron. Mater. Chem. Phys. 2013, 29-37.

31 Liu, Y.; Chen, T.; Wu, C.; Qiu, L.; Hu, R.; Li, J.; Cansiz, S.; Zhang, L.; Cui, C.; Zhu, G.; You, J.; Zhang, T.; Tan, W. Facile Surface Functionalization of Hydrophobic Magnetic Nanoparticles. J. Am. Chem. Soc. 2014, 136, 12552-12555. 
32 Wei, H.; Bruns, O. T.; Chen, O.; Bawendi, M. G. Compact Zwitterion-Coated Iron Oxide Nanoparticles for In Vitro and In Vivo Imaging. Integr. Biol. 2013, 5, 1.

33 del Pino, P.; Pelaz, B.; Zhang, Q.; Maffre, P.; Nienhaus, G. U.; Parak, W. J. Protein Corona Formation Around Nanoparticles - From the Past To the Future. Mater. Horiz. 2014, 1, 301-313.

34 Hachani, R.; Lowdell, M.; Birchall, M.; Hervault, A.; Mertz, D.; Begin-Colin, S.; Thanh, N. T. K. Polyol Synthesis, Functionalisation, and Biocompatibility Studies of Superparamagnetic Iron Oxide Nanoparticles As Potential MRI Contrast Agents. Nanoscale 2016, 8, 3278.

35 Kralj, S.; Rojnik, M.; Romih, R.; Jagodic, M.; Kos, J.; Makovec, D. Effect of Surface Charge on the Cellular Uptake of Fluorescent Magnetic Nanoparticles. J. Nanopart. Res. 2012, 14, 1151.

36 Verma, A.; Stellacci, F. Effect of Surface Properties on Nanoparticle-Cell Interactions. Small 2010, 6, 12-21.

37 Riegler, J.; Liew, A.; Hynes, S. O. Superparamagnetic Iron Oxide Nanoparticle Targeting of MSCs in Vascular Injury. Biomaterials 2013, 8, 1987-1994.

38 Blanco-Andujar, C.; Ortega, D.; Southern, P.; Nesbitt, S. A.; Thanh, N. T. K.; Pankhurst, Q. A. Real-Time Tracking of Delayed-Onset Cellular Apoptosis Induced by Intracellular Magnetic Hyperthermia. Nanomedicine 2016, 11, 121-136.

39 Gu, L.; Fang, R. H.; Sailor, M. J.; Park, J.-H. In Vivo Clearance and Toxicity of Monodisperse Iron Oxide Nanocrystals. ACS Nano 2012, 6, 4947-4954.

40 Feng, Q.; Liu, Y.; Huang, J.; Chen, K.; Huang, J.; Xiao, K. Uptake, Distribution, Clearance, and Toxicity of Iron Oxide Nanoparticles with Different Sizes and Coatings. Nat. Sci. Rep. 2018, 8, 2082.

\section{Table of Content}

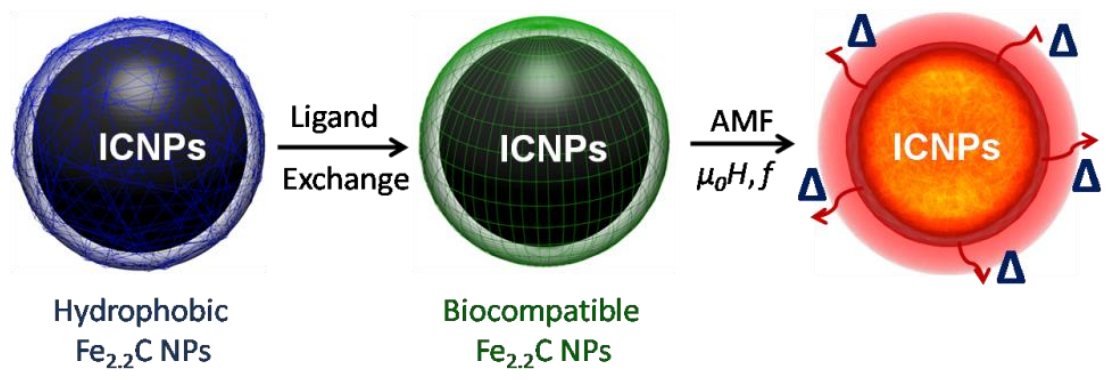


Highly magnetic $\mathrm{Fe}_{2.2} \mathrm{C}$ iron carbide nanoparticles displaying excellent specific absorption rates were successfully stabilized in aqueous media using specific dopamine-based ligands. Even after several months of exposure to water and air, iron carbide nanoparticles retained high heating power through magnetic induction. The nature of the ligands was proven to be a critical parameter to tune the biocompatibility and cellular-uptake of the considered nanoparticles. 